\title{
Patients' Perceived Quality of Family Physicians' Primary Care with or without 'Family Medicine' in the Clinic Name
}

\author{
Ka Young Kim, Kangjin Lim, Eal Whan Park*, Eun Young Choi, Yoo Seock Cheong \\ Department of Family Medicine, Dankook University College of Medicine, Cheonan, Korea
}

Background: Patients' perspectives of family medicine according to the physician's identity and role as a primarycare specialist need to be investigated. This study was conducted to investigate the perceived quality of the primary care of family medicine clinics as assessed by patients in a community setting.

Methods: Patients (or their guardians) visiting nine community family medicine clinics were surveyed using the Korean Primary Care Assessment Tool from April 2014 to June 2014. The scores of the Korean Primary Care Assessment Tool domains were compared according to the clinics' designation (or not) as 'family medicine' and the patients' recognition (or not) of the physicians as board-certified family medicine specialists.

Results: A total of 196 subjects responded to the questionnaire. They assessed the community clinics' quality of primary care as moderate to high. Of the clinics, those that were not designated as family medicine scored higher than those that were designated as family medicine $(\mathrm{P}<0.05)$. The group of patients that recognized a clinic as that of a board-certified family medicine specialist awarded higher scores than the non-recognition group in the domains of coordination function and personalized care $(\mathrm{P}<0.05)$.

Conclusion: The moderate to high scores for the community family medicine clinics' quality of primary care are encouraging. It seems that patients' recognition of the family physician's role and of the physician-patient relationship has a significant influence on their assessment of the quality of primary care.

Keywords: Family Practice; Primary Health Care; Quality of Health Care; Physicians 


\section{INTRODUCTION}

Family medicine was first introduced to Korea in 1978, and boardcertified family medicine specialists began to practice in 1987. Over the course of the succeeding 31 years, family medicine has become firmly established as a specialty of primary care in Korean medicine. The management of common diseases by family physicians rather than by other general physicians or specialists has contributed to significant medical cost savings. ${ }^{1,2)}$ Moreover, family medicine has, relative to other specialties, produced physicians who can practice primary care efficiently. ${ }^{1,3)}$

According to a 2006 research study using the Delphi method, primary care in Korea is defined as a medical field in which a private physician, who knows the patient's family and community well, cultivates a close doctor-patient relationship and manages healthcare resources appropriately to solve the common health problems of the people. This same study identified four core properties of primary care including first-contact care, continuity of relationship, comprehensiveness, and coordination, along with three complementary properties including total care, family/community-context, and community-centeredness. ${ }^{4}$

In 2008, the Korean Primary Care Assessment Tool (KPCAT) was developed to assess the quality of primary-care performance from the patient's perspective, and its validity was tested. ${ }^{5}$ The KPCAT was constructed by formulating and selecting items, and subjecting them to expert evaluation, principal component analysis, and validity testing under the conceptual framework of the recently developed definition of primary care. ${ }^{4,5)}$ This questionnaire, which enables patients and other healthcare consumers to assess primary-care services, has already been applied several times to evaluate the primary-care quality in Korea. $^{6-10)}$

According to the Korean Academy of Family Medicine's (KAFM) member registration database, 7,700 family physicians were actively practicing in 2014, although many of them did not designate their clinic as one for family medicine. In 2013, the KAFM surveyed members' opinions for or against changing the 'family medicine' specialty name, and canvassed suggestions for a new name. However, the survey results were not officially announced, and the issue of the possible name change was dropped. ${ }^{11)}$ In the present research, which is the first of its kind to have been conducted in Korea, ${ }^{12)}$ we used the KPCAT to investigate patients' perception of the quality of primary care by community family medicine clinics, and compared the assessment scores of those who had received primary care at clinics self-designated as family medicine with those who had received primary care at clinics not selfdesignated as family medicine. We hypothesized that the perceived quality of primary care would significantly differ according to the designation or non-designation of a clinic as family medicine as well as the patients' recognition or non-recognition of the practicing physician as a board-certified family medicine specialist.

\section{METHODS}

\section{Research Subjects and Methods}

We selected nine community clinics at which the doctor was a boardcertified family medicine specialist in practice for more than three years and a member of the Cheonan Primary Care Research Network. Of the clinics, four were self-designated as family medicine and five were not.

The KPCAT questionnaire for assessment of the quality of primary care is composed of five domains and 21 items in total, including five items in the 'first contact' domain, four in the 'comprehensiveness' domain, three in the 'coordination function' domain, five in the 'personalized care' domain, and four in the 'family/community orientation' domain. Each item is assessed on a five-point Likert scale, and the final scores are converted to a 100-point scale.

The questionnaire includes 10 questions concerning the following factors: socio-demographic indicators including age, sex, marriage status, education status, and monthly income; number of chronic diseases; the period of clinic utilization; whether or not the patients recognize that the clinic is that of a board-certified family medicine specialist; and whether or not they agree with the proposal to change the name of the family medicine specialty (if they agreed, they were invited to suggest a new name or names).

The survey was conducted from April 16, 2014 to June 9, 2014. Specially trained nurses or nursing aids surveyed 196 patients (or their guardians) in a waiting room prior to a doctor's appointment. The study was performed according to the guidelines of the Helsinki Declaration and underwent scrutiny of the Institutional Review Board of Dankook University Hospital.

\section{Statistical Analyses}

Frequency analyses of the categorical variables were performed. The mean scores of the quality of primary care were compared between family medicine-designated clinics and non-designated clinics using the Student t-test. The mean scores of the quality of primary care were compared according to whether or not patients recognized a clinic as that of a board-certified family medicine specialist using the nonparametric Mann-Whitney U-test. The IBM SPSS ver. 20.0 (IBM Co., Armonk, NY, USA) was used for the statistical analyses. The level of significance was designated as $\mathrm{P}<0.05$.

\section{RESULTS}

\section{Socio-Demographic Characteristics of Research Subjects}

A total of 326 questionnaires were distributed and 198 were collected. The response rate was $60.1 \%$. Two inadequate questionnaires were discarded due to missing data. One hundred and sixteen questionnaires were collected from clinics self-designated as family medicine, and 80 from those not self-designated as family medicine.

Among the respondents, 74 (37.8\%) were male and 122 (62.2\%) female. The average age was 45.3 (standard deviation $[\mathrm{SD}]=14.8$ ) years. 
The respondents whose monthly income was over 3 million won numbered $122(62.2 \%)$. As for education status, those who continued past high school numbered $163(83.2 \%)$.

The socio-demographic characteristics and utilization variables between the self-designating and non-self-designating groups were compared. According to the results, there were no significant statistical inter-group differences for any of the variables except for the period of clinic utilization $(\mathrm{P}>0.05)$ (Table 1$)$.

\section{Quality of Primary Care (Korean Primary Care}

\section{Assessment Tool) Scores as Assessed by the Patients}

The overall average score of the quality of primary care was 70.08 ( $\mathrm{SD}=15.64)$. The average score of the domain of personalized care was rated the highest at $83.9(\mathrm{SD}=14.61)$. The average score of the domain of first contact was 81.7 ( $\mathrm{SD}=17.6$ ), of family/community orientation it was 72.8 ( $\mathrm{SD}=20.8)$, and of comprehensiveness it was $56.5(\mathrm{SD}=26.0)$.
The average score of the domain of coordination function was rated the lowest at $42.22(\mathrm{SD}=26.95)$ (Table 2).

\section{Comparison of Korean Primary Care Assessment Tool Scores by Designation of Clinic}

Regarding the KPCAT scores according to clinic designation, the total score of the family medicine-designated group was 66.5 ( $\mathrm{SD}=15.9$ ), and that of the non-designated group was $75.3(\mathrm{SD}=13.8)$. This result represented a significantly higher rating for the non-designated group $(\mathrm{P}<0.001)$. In fact, this group's scores were significantly higher in three of the four KPCAT domains, the exception being for coordination function (Table 2).

Table 1. Socio-demographic characteristics of study subjects

\begin{tabular}{|c|c|c|c|c|}
\hline Characteristic & Total $(\mathrm{N}=196)$ & $\begin{array}{l}\text { Patients of designated family medicine clinics } \\
\qquad(\mathrm{N}=116)\end{array}$ & $\begin{array}{l}\text { Patients of non-designated family medicine } \\
\text { clinics }(\mathrm{N}=80)\end{array}$ & P-value* \\
\hline Age (y) & $45.3 \pm 14.8$ & $46.7 \pm 14.6$ & $43.3 \pm 14.9$ & 0.059 \\
\hline Sex & & & & 0.551 \\
\hline Male & $74(37.8)$ & $46(39.7)$ & $28(35.0)$ & \\
\hline Female & 122 (62.2) & $70(60.3)$ & $52(65.0)$ & \\
\hline Marriage status & & & & 0.180 \\
\hline Married & 163 (83.2) & $100(86.2)$ & $63(78.8)$ & \\
\hline Not married & $33(16.8)$ & $16(13.8)$ & 17 (21.2) & \\
\hline Income (million won/mo) & & & & 0.084 \\
\hline$<1$ & $21(10.8)$ & $14(12.1)$ & $7(8.8)$ & \\
\hline $1-2$ & $53(27.0)$ & $36(31.0)$ & $17(21.2)$ & \\
\hline$\geq 3$ & $122(62.2)$ & 66 (56.9) & $56(70.0)$ & \\
\hline Education (y) & & & & 0.794 \\
\hline$<10$ & $33(16.9)$ & $16(13.8)$ & 17 (21.2) & \\
\hline $10-12$ & 73 (37.2) & $44(37.9)$ & 29 (36.3) & \\
\hline$\geq 13$ & $90(45.9)$ & 56 (48.3) & $34(42.5)$ & \\
\hline No. of chronic diseases & & & & 0.756 \\
\hline 0 & $133(67.9)$ & $80(69.0)$ & $53(66.3)$ & \\
\hline$\geq 1$ & $63(32.1)$ & $36(31.0)$ & $27(33.7)$ & \\
\hline The period of clinic utilization (y) & & & & 0.005 \\
\hline$\leq 5$ & $128(65.3)$ & 68 (58.6) & $60(75.0)$ & \\
\hline$>5$ & $68(34.7)$ & 48 (41.4) & $20(25.0)$ & \\
\hline
\end{tabular}

Values are presented as mean \pm standard deviation or number (\%).

*Obtained from Student t-test for the continuous variables and $\chi^{2}$ test for the categorical variables when comparing the differences between the two subgroups.

Table 2. Primary-care scores for the five domains of the Korean Primary Care Assessment Tool according to the designation of the clinic as family medicine

\begin{tabular}{|c|c|c|c|c|c|}
\hline Domains & No. of items & Total $(\mathrm{N}=196)$ & $\begin{array}{l}\text { Designated family medicine } \\
\text { clinic group }(\mathrm{N}=116)\end{array}$ & $\begin{array}{l}\text { Non-designated family medicine } \\
\text { clinic group }(\mathrm{N}=80)\end{array}$ & P-value* \\
\hline First contact & 5 & $81.7 \pm 17.6$ & $78.6 \pm 19.4$ & $86.3 \pm 13.3$ & 0.001 \\
\hline Comprehensiveness & 4 & $56.5 \pm 26.0$ & $50.1 \pm 24.5$ & $65.6 \pm 25.5$ & $<0.001$ \\
\hline Coordination function & 3 & $42.2 \pm 27.0$ & $40.1 \pm 25.5$ & $45.3 \pm 28.8$ & 0.183 \\
\hline Personalized care & 5 & $83.9 \pm 14.6$ & $81.6 \pm 14.9$ & $87.1 \pm 13.7$ & 0.084 \\
\hline Family/community orientation & 4 & $72.8 \pm 20.8$ & $68.8 \pm 21.9$ & $78.8 \pm 17.5$ & $<0.001$ \\
\hline Total average score & 21 & $70.1 \pm 15.6$ & $66.5 \pm 15.9$ & $75.3 \pm 13.8$ & $<0.001$ \\
\hline
\end{tabular}

Values are presented as mean \pm standard deviation.

${ }^{\star}$ Obtained from Student t-test for the continuous variables when comparing the mean differences between the two subgroups. 
Table 3. Primary-care scores for the five domains of the Korean Primary Care Assessment Tool according to the patients' recognition of the board-certified family medicine specialist

\begin{tabular}{lccccc}
\hline \multicolumn{1}{c}{ Domains } & No. of items & Total $(\mathrm{N}=196)$ & $\begin{array}{c}\text { Family medicine recognition } \\
\text { group }(\mathrm{N}=177)\end{array}$ & $\begin{array}{c}\text { Family medicine non-recognition } \\
\text { group (N=19) }\end{array}$ & P-value \\
\hline First contact & 5 & $81.7 \pm 17.6$ & $82.5 \pm 16.8$ & $74.7 \pm 22.9$ & 0.210 \\
Comprehensiveness & 4 & $56.5 \pm 26.0$ & $57.0 \pm 25.0$ & $51.6 \pm 34.3$ & 0.632 \\
Coordination function & 3 & $42.2 \pm 27.0$ & $43.6 \pm 27.5$ & $28.9 \pm 17.0$ & 0.033 \\
Personalized care & 5 & $83.9 \pm 14.6$ & $84.8 \pm 13.6$ & $74.7 \pm 20.0$ & 0.027 \\
Family/community orientation & 4 & $72.8 \pm 20.8$ & $73.4 \pm 20.4$ & $67.1 \pm 23.8$ & 0.218 \\
Total average score & 21 & $70.1 \pm 15.6$ & $70.9 \pm 15.0$ & $62.3 \pm 19.7$ & 0.056 \\
\hline
\end{tabular}

Values are presented as mean \pm standard deviation.

*Obtained from the Mann-Whitney U-test when comparing the mean differences between the two subgroups.

\section{Comparison of Korean Primary Care Assessment Tool Scores according to Patient Recognition of the Physician as a Board-Certified Family Medicine Specialist}

The KPCAT total score for the group that recognized that the family medicine specialist was board-certified was 70.9 ( $\mathrm{SD}=15.9)$, and that for the non-recognition group was $62.3(\mathrm{SD}=19.7)$. Whereas the score was higher in the recognition group, the difference was statistically insignificant $(\mathrm{P}=0.056)$. As for the KPCAT domains, the scores for coordination function and personalized care were significantly higher in the recognition group $(\mathrm{P}<0.05)$ (Table 3$)$.

\section{DISCUSSION}

The results of this research show that patients who visited nine community family medicine clinics rated the quality of primary care as moderate to high. The comprehensiveness and coordination function domains of primary care were assessed as moderate, while the first contact, personalized care, and family/community orientation domains were evaluated as high. These results are similar to those of previous research with hypertensive patients who continually visited family physicians' clinics. ${ }^{9)}$

The present results further showed that patients who used clinics that were not self-designated as family medicine, assessed the quality of primary care as higher than those who used self-designated clinics. This finding is contrary to our research hypothesis, which was that physicians designating their clinics as family medicine would be considered more responsible and confident in their practice, reflective of the first contact, comprehensiveness, continuity of care, and coordination properties of primary care.

The reason that our hypothesis is contrary to the results of our research is that whether or not family medicine is designated in a clinic's name, it did not affect the patient's assessment of the quality of that clinic's primary care. Rather, a family physician's relationship with his/ her patients and their own competence in the practice of primary care strongly affected a patient's assessment of that clinic.

Meanwhile, the group of patients that recognized the visited clinic as that of a board-certified family medicine specialist assessed the quality of primary care to be higher than the group that did not so recognize the visited clinic. Baek et al. ${ }^{13)}$ reported that patients who had visited a private physician rated the quality of primary care to be higher than those who had not. Consistent with this, the present research found that patients' recognition of the practicing physician as a family medicine specialist, as well as the family physician's responsible role as a private physician, were important factors affecting patients' assessment of primary care, and that the clinic title was relatively unimportant.

Designating a clinic as family medicine has served, since family medicine's very beginnings, to establish and emphasize its specialty. Such a designation is meant to differentiate the practicing family physician from other specialists; that is, it indicates that the practicing physician considers the family as a unit of care and, as such, evaluates a patient's biomedical situation as it relates to his/her family, managing it in such a way as to emphasize family-centered care. ${ }^{14)}$

However, it should be recognized that what is more important than the assertion of the family medicine specialist's accreditation, is the competence and capacity of the family physician to implement primary care effectively. In most family medicine residency programs, residents complete a 2-3 months' rotation period in the department of family medicine every year, during which time they gain experience in the implementation of family-centered healthcare as a private family physician in real practice. Thanks to this education, family physicians' future real practice in their respective communities can be in accord with the name of their specialty; indeed, it is possible that designating their clinics as family medicine will come to fully reflect their identity as family physicians and competent primary-care practitioners.

The main limitation of this research is the small sample size. Therefore, the obtained results cannot be generalized. Further research with larger subject cohorts is necessary. A second limitation is the arbitrary selection of the questionnaire respondents in each clinic, which could have incurred selection bias. A third limitation is the fact that the research results could not be adjusted according to the characteristics of the clinics' respective practices, including average consultation time per patient, number of patients per day, specific diseases treated, and practicing physicians' attitudes to family medicine.

Notwithstanding the limitations of the research, it is certainly meaningful that the quality of the primary care of family medicine clinics was assessed by patients in a community setting. The fact that patients perceived the quality of primary care as high in the domains of first 
contact, personalized care, and family/community orientation is particularly encouraging. The quality of primary care was perceived as high when patients recognized that the practicing physicians were board-certified family physicians, even though their clinics were not designated as family medicine. We believe that physician's behaviors in practice, patient education materials, the characteristics of the physician-patient relationship, and the attitude of office personnel can provide patients with clues to recognizing a practice as a family medicine clinic.

\section{CONFLICT OF INTEREST}

No potential conflict of interest relevant to this article was reported.

\section{REFERENCES}

1. Kang JH. Research of family medicine. In: The Korean Academy of Family Medicine, editor. Textbook of family medicine. 2nd ed. Seoul: Gechukmunhwasa; 2003. p. 79-87.

2. Jeong EK, Moon OR, Kim CY. A study on the practice variations according to physician characteristics. Korean J Prev Med 1993;26:61427.

3. Kim CH, Moon OR. A study on the most frequent diseases of health insurance program and the primary care physicians in Korea. Health Policy Manag 1993;3:124-45.

4. Lee JH, Choi YJ, Volk RJ, Kim SY, Kim YS, Park HK, et al. Defining the concept of primary care in South Korea using a Delphi method. Fam Med 2007;39:425-31.
5. Lee JH, Choi YJ, Sung NJ, Kim SY, Chung SH, Kim J, et al. Development of the Korean primary care assessment tool--measuring user experience: tests of data quality and measurement performance. Int J Qual Health Care 2009;21:103-11.

6. National Health Insurance Corporation. Effectiveness assessment in primary care. Seoul: National Health Insurance Corporation; 2008.

7. Choi YG, Kim K, Choi YJ, Sung NJ, Kim J, Park JH, et al. Patient assessment of primary care of health cooperative clinics in South Korea. Korean J Fam Med 2010;31:765-77.

8. Sung NJ, Suh SY, Lee DW, Ahn HY, Choi YJ, Lee JH, et al. Patient's assessment of primary care of medical institutions in South Korea by structural type. Int J Qual Health Care 2010;22:493-9.

9. Park JH, Kim KW, Sung NJ, Choi YG, Lee JH; Korean Primary Care Research Group. Association between primary care quality and health behaviors in patients with essential hypertension who visit a family physician as a usual source of care. Korean J Fam Med 2011;32:104-11.

10. Jung JW, Sung NJ, Park KH, Kim SW, Lee JH. Patients' assessment of community primary and non-primary care physicians in Seoul city of South Korea. Korean J Fam Med 2011;32:226-33.

11. Kim YS. Current issues and prospect of KAFM. Proceedings of the 2013 Spring Conference of Korean Academy of Family Medicine; 2013 Apr 6; Daegu, Korea. Seoul: Korean Academy of Family Medicine; 2013.

12. Jeong JW, Sung NJ. Present status of papers on the primary care quality assessment in Korea. Korean J Fam Med 2009;30:525-32.

13. Baek KH, Park EW, Hong NE, Jo JW, Choi EY, Jung YS. Is primary care of family medicine better in quality than that of other specialties? J Korean Acad Fam Med 2005;26:404-11.

14. Stein HF. Family medicine's identity: being generalists in a specialist culture? Ann Fam Med 2006;4:455-9. 